I W. CORNFORTH, who shares this . year's Nobel Prize in Chemistry with V. Prelog, is now taking up, at the age of 58, a new full-time appointment as Royal Society Research Professor in the Department of Applied Science in the University of Sussex. $\mathrm{He}$ began his distinguished career in organic chemical research in Australia: he graduated at the University of Sydney and was awarded the University Medal in Organic Chemistry. This was followed by an 1851 Exhibition Overscas Scholarship to the UK, which he held from 1939 to 1942 in the Dyson Perrins Laboratory at Oxford with Robert Robinson, and he has remained in the UK since.

His early work was on Australian plant materials (with J. C. Earl) and he moved in Robinson's laboratory naturally. Inevitably in that environment he was attracted to the problem of the laboratory synthesis of cholesterol, and when the Second World War extended his stay in the UK, he was drawn into the maelstrom of the penicillin problem. In 1946 he joined the staff of the Medical Research Council at the National Institute for Medical Research and a career of individual work began to take shape; a summary is almost impossible to make: it would be a task of selecting high lights in a dazzling array of subjects. Enquiry into natural products, laboratory synthetical methods, fundamental reactions of biosynthesis, isotope techniques, reactions applicable to manufacture of medicinal products-all were grist to his mill; one has only to start discussion of a structural or synthetic problem with him to provoke a flow of 'graphite and cellulose' solutions. The only drawback to consultation is his complete deafness, which makes the problem of getting a word in edgeways and saying "yes, but" or

\section{Kennedy's good deed}

\section{THOMAS H. JUKES}

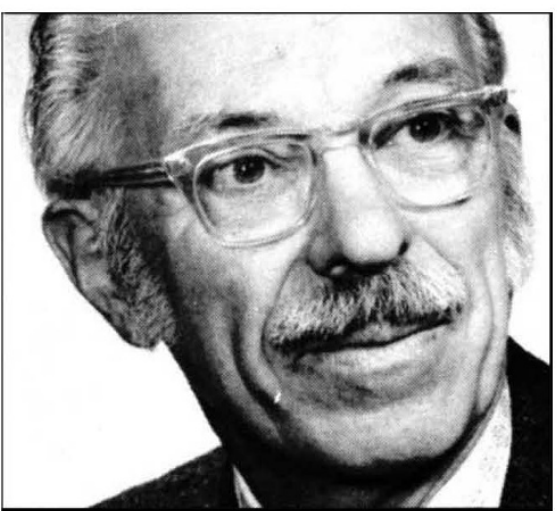

"I thought of that" a difficult one.
The handicap of deafness he has overcome magnificently, particularly with the aid of his wife, Rita, who is herself an organic chemist of great skill. Cornforth's relation with Robert Robinson is best put in his own words.

\section{Cornforth's prize}

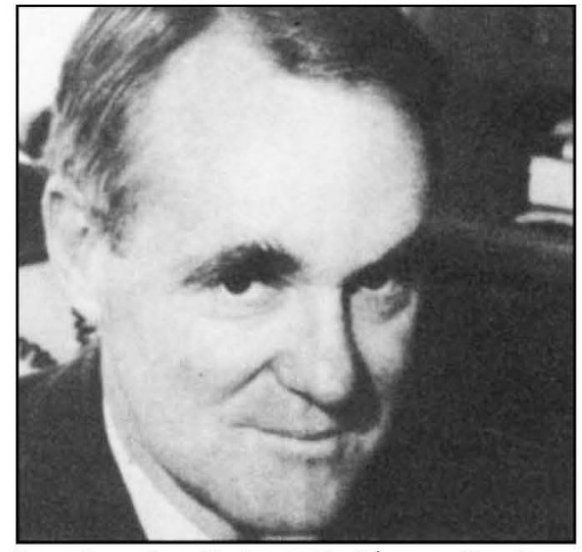

Opening the Robert Robinson Lecture he gave to the Chemical Society in 1972 he said: "Our friendship . . . for more than 30 years has been a continuous sequence of differences of opinion". Reorientation of Cornforth's work, after the publication of some papers on miscellaneous subjects from the National Institute for Medical Research, came about in two ways in 1950. First, as a consequence of the Medical Research Council taking the lead in this country in the search for a source from which cortisone could be manufactured, and its involvement with the National Research Development Corporation, the workers at the National Institute were mobilised. Hecogenin, the steroid sapogenin from

ON September 8, the US Senate passed, by 61 votes to 29 , a bill (S-963) introduced by Senator Kennedy to ban the use of diethylstilboestrol (DES) in growing beef cattle. The same bill would authorise the use of DES as a contraceptive after sexual intercourse only in rape, incest or "a comparable medical emergency" (the "morningafter pill').

The bill carefully provides that the ban for beef must first be approved by the National Cancer Institute. This will be easy. Scientists of the National Cancer Institute have already testified before congressional hearings that one molecule of DES may cause cancer. Quite a lot of cancer cases were thus implied in a world population of $3 \times 10^{\circ}$ which is presumably exposed to molecular levels of DES in the air and water. One morning-after pill contains sisal (Agave sisalana) was found to be such a raw material, which, on the basis of fundamental chemical work at Mill Hill and development in collaboration with the staff of Glaxo Laboratories became of considerable commercial importance.

The second direction of development of Cornforth's work came in the early $1950 \mathrm{~s}$ in association with George Popják, then in the Biochemistry Division at Mill Hill and later at the Medical Research Council's Radiopathology Research Unit. This work, which led, finally, to the results of fundamental theoretical significance for enzymology that have earned the Nobel Award, began with the examination of the problem of the route of biosynthesis of squalene from mevalonic acid. Development of new techniques for using isotopically labelled compounds, with such incidental ingenuities as the characterisation and orientation of the three hydrogen atoms of a methyl group by labelling with protium, tritium and deuterium followed, along with the extension to the study of enzyme stereochemistry on a wider basis.

In 1962, Cornforth and Popják became joint directors of the Shell Research Milstead Laboratory of Chemical Enzymology at Sittingbourne, an establishment that in the best tradition of schoolboy humour was dubbed at its inauguration the "PopCorn Laboratory". Unhappily Popják broke the link when he migrated to the USA. No doubt Cornforth's new laboratory in the University of Sussex will acquire some title of affection appropriate to the unique individuality of its presiding genius and certainly occupy an important place among the world's centres of scientific research.

\section{R. K. Callow}

$7 \times 10^{19}$ molecules.

Diethylstilboestrol is a known human carcinogen. Even worse, it is synthetic and man-made; a self-inflicted wound. Herbst, who discovered its carcinogenicity in human subjects, has calculated its cancer-causing potency: less than 4 cases per 1,000 in the female progeny of pregnant women receiving $1.5 \mathrm{mg}\left(3 \times 10^{18}\right.$ molecules $)$ of DES per day. He also notes that "there has been no documented correlation of maternal DES therapy with the development of cancer in males". Incidentally, DES is widely used as an anti-cancer drug in prostatic cases.

The intake of DES per capita from beef may be calculated from data for the residues found in implanted cattle, and the consumption of beef liver, $0.7 \mathrm{~kg}$ a year $\left(0.12\right.$ parts per $\left.10^{\circ}\right)$, plus beef muscle meats, $52 \mathrm{~kg}$ a year $(0.012$ 